\title{
Visual Impairment People Towards Vision 2020 - A Review
}

\author{
Jayasudha Subburaj', P. Keerthana² and A. Shobana ${ }^{3}$ \\ 'Department of Master of Computer Applications, Sri Krishna College of Engineering and Technology, \\ Coimbatore - 641008, Tamil Nadu, India; jayasudhasubburaj@gmail.com \\ 2Department of Information Technology, Sri Krishna College of Engineering and Technology, \\ Coimbatore-641008, Tamil Nadu, India; keerthanap@skcet.ac.in \\ ${ }^{3}$ Department of Science and Humanities, Sri Krishna College of Engineering and Technology, \\ Coimbatore -641008,Tamil Nadu, India; shobanaa@skcet.ac.in
}

\begin{abstract}
Objectives: To make a perception about the differently disabled people on their problems and responsibility of the society to overcome their problems. Methods/Statistical Analysis: The review is done by the articles which deals with global visual impairment data along with device and technologies mainly used for Visually Impaired people. For analysis, different methods are analyzed to identify the causes and device implementation to enable an independent life. The characteristics of differently abled people are well identified through the analysis. Findings: In vision 2020 survey, various impacts on specialized people using smart technologies reduce their vision problems. Application/Improvements: This framework design measures the merits and demerits of smart technologies used to maintain the quality life of disable people.
\end{abstract}

Keywords: Aided Devices, Disabled People, Sensor Network, Visual Impairment

\section{Introduction}

Technology helps for differently abled people to led a normal life. Differently Abled people use technology for upgrading and live easier life. One billion people of over population suffer from different forms of disabilities. In India out of the 253 million populations, $20 \%$ persons are disabled in different ways. Among the disabled population $56 \%(1.5 \mathrm{Cr})$ are males and $44 \%$ $(1.18 \mathrm{Cr})$ are female. The commonness of disability is premier in developing countries like India. Being differently abled is a complex phenomenon, has shifted from individual impairment to social phenomenon. Disability of persons includes the incurable impairments which may obstruct their full and valuable participation in the society.

$\mathrm{In}^{\mathrm{l}}$ Disability is being deficient in performing normal activity like a normal person throughout his life span. Disability is a term represents an impairment, activity limitation and participation restriction. An impairment is a problem, which is limited an activity for an individual into execute their daily routine task. The participation restriction problem is faced by an individual in all times of their routine life.

The disabled people entrusted on somebody to do all the things. The $e^{2}$ technology advancements help the disabled people to do things that would have never been possible before by them. The technology is being act as a helping hand for people with disabilities.

There are many types of disabilities such as $\mathrm{s}^{3-5}$ intellectual, physical, sensory, and mental illness. The development of accessibility apps and gadgets were used to help the disabled people on our contemporary society. The improved quality life is assured with advanced technologies for the disabled people. Also, people with defects have been experiencing socialpsychological problems in the society in the sense that society defines them as function-less and that they cannot positively contribute to the society. Thus they live in isolation and exclusion. 
We design a frame work to explain the steps taken to survey about the visually impaired. (Figure 1) framework defines that the visually impairment problem is specifically mentioned among different ability people. The 12 papers are reviewed thoroughly to evaluate the conditions, responsibilities and devices used for independent live of visually impaired people.

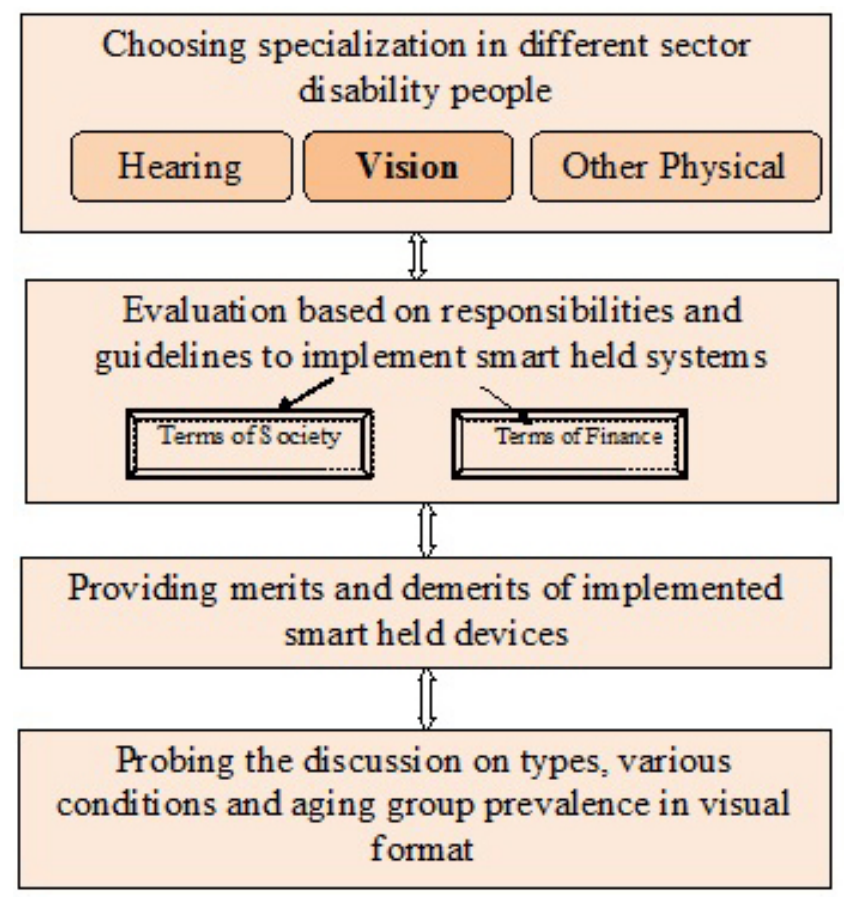

Figure 1. Framework for analysis.

\subsection{Challenges of Disabled People Sector}

In our society there are many challenges are faced by differently abled people in all ways. The general accostation of those people are discussed as follows,

- Children with disabilities remain invisible to the education system

- Family unsupportive

- Poor access of training in teaching and knowledge

- Lack of public support

- No inclusive of governance, financing and policy planning

- Economic ${ }^{\underline{6}}$, physical and socio/physiological challenges

- Accessibility, availability and utilization of rehabilitation services

- Lack of facilities in transport systems

- Difficulties in modern or rural area
The challenges are resolved by enhancing the education system and society policies in all rehabilitation services. The government sectors and WHO organization has to take the responsibility to overcome the challenges in the disability sector.

- Need to give the revise education curriculum

- Need to improve the infrastructures specialized for disabled students

- Need to conduct awareness disability welfare program in world wide

- Need to afford transport facility which is availed for all specialized disabled people

- Need to build more blairs for safety and comfortable toilet environment

The challenges in the background of economic and society of the disabled people arise out of the discrimination. The lack of resources in economic side creates poverty to aid them in difficult to lead their daytoday life.

\section{Visual Impairment}

This study illustrates the survey of problems and device usage for visually impaired people. Inability to see a normal problem which is easily identified by a normal people. It involves an issue with sight which interferes with all aspects of society. The visual impairment may include the both partial sight and blindness causes.

The signs of visual impairment

- Unfocused eye movement together

- Unusual habits

- Eyes tear excessively

- Reddened eyes or lids

- Encrusted eyelids

The different conditions of vision problems are ${ }^{7}$ blindness, low vision and visually impaired associated with the level of causes. The severe vision loss leads to dependent live for the people who are suffered to fulfill their needs in all tasks.

\subsection{Perlustration of Devices and Technologies}

\subsubsection{Tele Assistance}

For Chronic and sick people, to help them to maintain their daily life by their own potential risks. The ${ }^{7-9}$ teleassistance is a reliability service based system relies on self adaptation. 


\section{Advantages:}

- Self adaptation

- Easy to implement in adhoc environment

- Useful to evaluate complex problems

\section{Disadvantages:}

- Service become unavailable

- Server may fail

- Variation of service response time

- Difficult to change the workflow

- Abnormal sequence change

\subsubsection{Voice Maps}

The voice maps play significant role in the life of visually impaired people in all their aspects. They used audio type of information more than the other types of devices. The information will be helpful during their travel over the places. The Global positioning system is used to estimate the information from the vehicle movement. The voice activation features are enabled using sensors in all devices. The system is designed with human voice interrupt services. The response framework is also premeditated in between the device and the user. The 3 tier architecture of GPS is used along with programming modules.

\section{Advantages:}

- More convenient

- Easy identification of vehicle position changes

- Addition of new modules are easy

- Adequate reliability

- $\quad$ Sensed traffic alerts

\section{Disadvantages:}

- Data loss is more

\subsubsection{Rampe}

RAMPE $^{1}$ is a device to help out the blind people to know learn about the information. The device is used to represent the vocal messages and present the information to the blind people. The device framework is constructed to adapt the characteristics of types of all information. The mobility characteristic is improved while transferring the information. A handheld personal digital assistant is enabled with an embedded setup to increase the autonomy.

\section{Advantages:}

- Quick response to real time information

- Easy to handle moving scenarios

- Extend the use into person with reduced mobility

\section{Disadvantages:}

- Data driven application

- $\quad$ Service failure may possible

\subsubsection{Mobile Assistance}

The visual impaired people lead the life without the supporters and aids are very tough in ancient days. The real time technologies are used to increase their confidence level infront of the other society people. The mobile technologies take part in a major role in the communication of the blind people. Most of the applications had developed to make realistic life for their life. Mobile assistance is worked with the survey of quessionaires collected from various generes.

Advantages:

- Easy accessing of geographical information

- Rapid web browsing

- Voice expendability for both blind and low vision people.

- Complex object recognition

- Helpful for readability in low vision problem

\section{Disadvantages:}

- Difficult to make text entry and touch operations

- Enclose inaccessible applications

- Dilemma in speech output and poor vision.

\subsubsection{NavBelt}

Navbelt is a programmed travel aid for the blind people with all features. The framework is constructed using personal computer and ultrasonic sensors. The sensors are processed by set of instructions. They convey the information through sensors and it relies on headphone interface. The belt enables trustworthy to walk alone without any subordinates. The modes of operation categorized into guidance and image to enable the user to walk alone.

\section{Advantages:}

- Suitable for Reliable real time environment

- More Time consumption

- Active scanning

Disadvantages:

- A reduced amount of enunciate in guidance mode

- Impenetrability to conveying information when the failure occurs. 


\subsubsection{Guidance Cane}

Guidance cane is useful in conveying messages to the visually impaired people. It is reliable to convey the voice messages. The ${ }^{10}$ device setup made by using array of sensors mounted on semicircular join. The acoustic signals guide the passengers in the desired direction. The guidance mode of operation is used to increase the rate of transmitted rate.

\section{Advantages:}

- Reliable

- Low cost

\section{Disadvantages:}

- Problem in decreased transmitted rate

\subsubsection{Haptic Direction Indicator}

Here, Virtual objects are created by the sense of touch works. The haptic indicator is used to safe the people from the dangerous situations.

\section{Advantages:}

- Frequent user navigation

- Increased sensorium

\section{Disadvantages:}

- Unaccuracy

- Low speed recognition

\section{Methodology}

Figure 2 in methodology of survey of various devices based on the screening of peer reviewed papers. The first stage of revision includes the references and causes of visual impairment analysis. The dataset is added to define the categories of visual impairments among different aging group people. The rapid analysis is done by using various records of World Health Organization. The undesirable dataset is removed and followed a preprocessing to represent the causes and effects of visual impairment $\frac{11}{}$, blindness and vision loss. The final representation illustrates the percentage of people affected by visual impairment in comparison with all over world. The articles which are specified the visual impairment due to older age people had taken into account for rapid assessment of study.

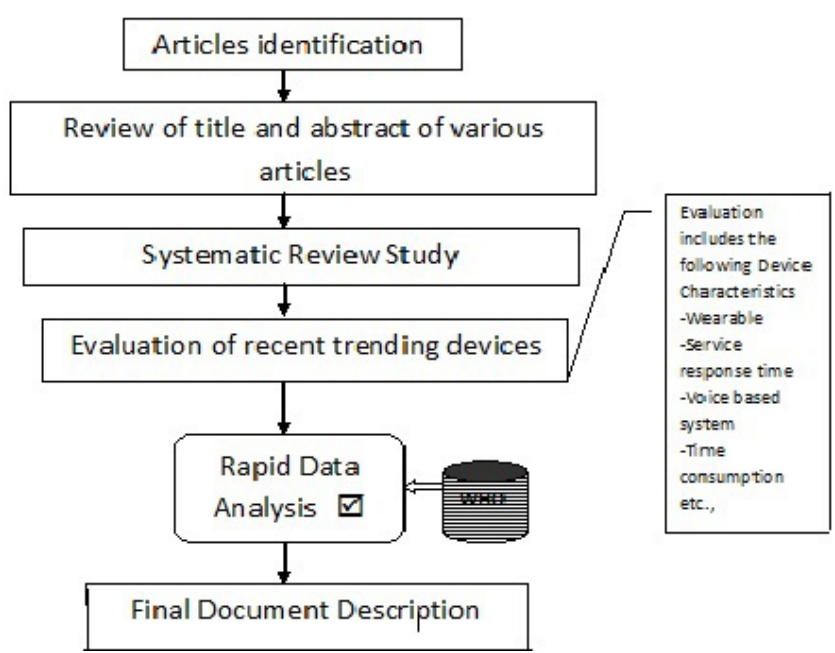

Figure 2. Methodology of visual impairment survey.

\section{Results and Discussion}

A description of studies about the visual impairment is given as the country specified problems in eyesight in Table $1 \frac{12,13}{2}$. The population based survey is used to estimate the proportion of visually impaired people among blindness and low vision category. The survey is done by undertaking different age groups along with visual impairment. Figure 3 shows that the three difficult conditions of vision problems among overall population by 2017. The WHO (World Health Organization) releases global visual impairment to create the awareness of vision loss in all fields. The study of 12 papers narrates that the older age grouping people mostly affected by the visual impairment from 2010 to 2015. (Figure 4) illustrates the global blindness, low vision and visual impairment of different age grouping people.

Table 1. Comparison between types of effects in eyes in India

\begin{tabular}{|l|c|c|c|}
\hline Country & Blind (\%) & Low Vision (\%) & $\begin{array}{c}\text { Visually } \\
\text { Impaired (\%) }\end{array}$ \\
\hline India & 6.8 & 43.6 & 53 \\
\hline
\end{tabular}

This study discusses ${ }^{14}$ the impacts of visually impaired people and anlysis of various devices along with merits and demerits. The innovated smart assistive technologies and devices are used to reduce the cataract problems and different aging group problems. 


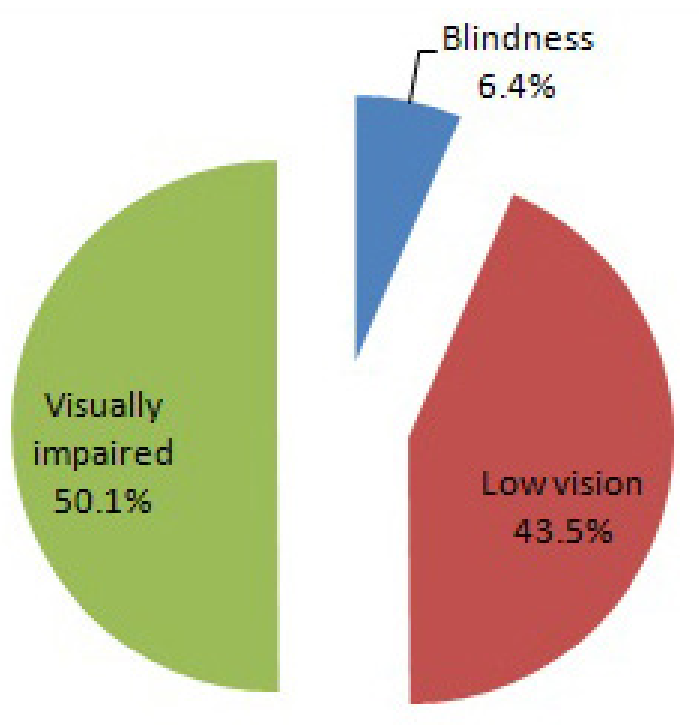

Figure 3. Comparison among different conditions of vision problems.

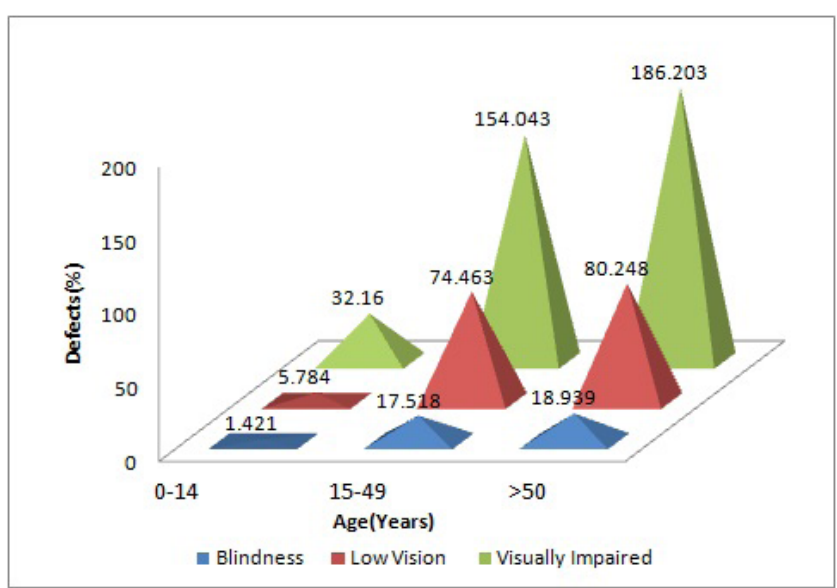

Figure 4. Comparison among different aging groups of vision problems.

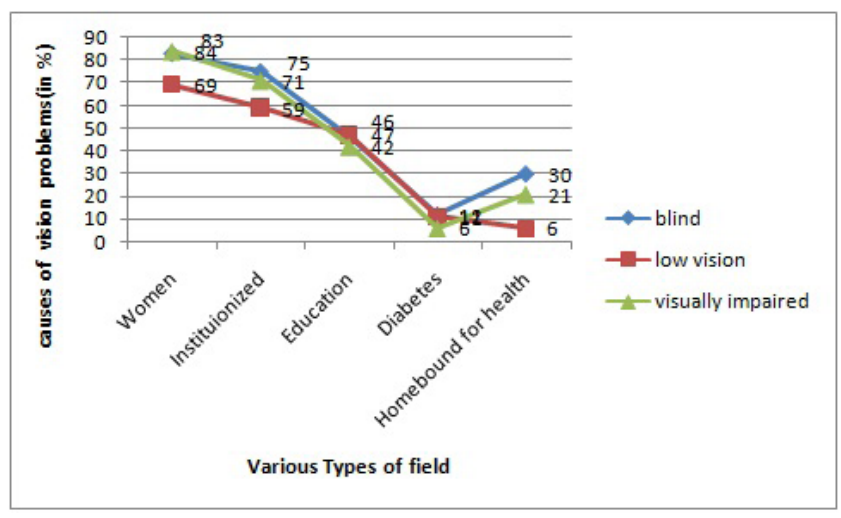

Figure 5. Representaion of survey among various clinic characteristics.
The study survey based model indicates the significance increase in visually impaired along with other conditions in Figure 5. The device usage for visually impairment should reduce the burden of visually impaired people. In India, the vision problem has a significant role among the overall population. The deficiency is identified and rectified by the initial stage in order to avoid the severe vision problems.

\section{Conclusion}

The designed framework will enhance the review of all types of disabled problems. The discussion results in the review of problems and devices used by the visually impaired people in the field of sensor networks. The visually impaired people lead an independent live with the helping of new innovation and assistive technologies. The identified vision problems may be curable or incurable according to the habit of people. But the device and technology implication should be reduced the difficulties of visually impaired people. The limitations on the mobility systems are also should be minimized for those people in their environment. The future study will extend to the research in the reduction of cost and size parameter in smart held devices for disability people.

\section{References}

1. Ghali NI, Soluiman O, El-Bendary N, Nassef TM, Ahmed SA, Elbarawy YM, Hassanien AE. Virtual reality technology for blind and visual impaired people: reviews and recent advances. In Advances in Robotics and Virtual Reality. Springer, Berlin, Heidelberg. 2012; p. 363-85. https://doi. org/10.1007/978-3-642-23363-0_15

2. Moore N. The information needs of visually impaired people. A Review of Research for the RNIB. 2000; p. 1-63.

3. Klaver CC, Wolfs RC, Vingerling JR, Hofman A, de Jong PT. Age-specific prevalence and causes of blindness and visual impairment in an older population: the Rotterdam Study. Archives of ophthalmology. 1998; 116(5):653-8. https://doi. org/10.1001/archopht.116.5.653 PMid:9596502

4. Albouys-Perrois J, Laviole J, Briant C, Brock AM. Towards a multisensory augmented reality map for blind and low vision people: A participatory design approach. Proceedings of the CHI Conference on Human Factors in Computing Systems. 2018; p. 1-629. https://doi.org/10.1145/3173574.3174203

5. Jothimani A, Edward S, Divyashree GK. Object Identification for Visually Impaired. Indian 
Journal of Science and Technology. 2016; 9(1):1-5. https://doi.org/10.17485/ijst/2016/v9iS1/108446

6. Fricke TR, Jong M, Naidoo KS, Sankaridurg P, Naduvilath TJ, Ho SM, Wong TY, Resnikoff S. Global prevalence of visual impairment associated with myopic macular degeneration and temporal trends from 2000 through 2050: systematic review, meta-analysis and modelling. British Journal of Ophthalmology. 2018; 102(7):855-62.https://doi. org/10.1136/bjophthalmol-2017-311266 PMid:29699985 PMCid:PMC6047154

7. Rowe FJ, VIS Writing Group, Wright D, Brand D, Maan T, Peel S, Akerman N, Dodridge C, Howard C, Shipman T, Sperring U. Vision in Stroke cohort: Profile overview of visual impairment. Brain and Behavior. 2017; 7(11):e00771. https://doi. org/10.1002/brb3.771 PMid:29201538 PMCid:PMC5698855

8. Wong YL, Sabanayagam C, Ding Y, Wong CW, Yeo AC, Cheung YB, Cheung G, Chia A, Ohno-Matsui K, Wong TY, Wang JJ. Prevalence, Risk Factors, and Impact of Myopic Macular Degeneration on Visual Impairment and Functioning Among Adults in Singapore. Investigative Ophthalmology \& Visual Science. 2018; 59(11):4603-13. https://doi.org/10.1167/iovs.18-24032 PMid:30242361

9. Siddiqui AA. The Current State of Health Sciences Research in the Country: What are the Needed Steps to Improve the Research Quality. Journal of Dow University of Health Sciences. 2017; 11(3):61-2.
10. Chang KF, Chang KH, Chi WC, Huang SW, Yen CF, Liao HF, Liou TH, Chao PZ, Lin IC. Influence of visual impairment and hearing impairment on functional dependence status among people in Taiwan - An evaluation using the WHODAS 2.0 score. Journal of the Chinese Medical Association. 2018; 81(4):376-82. https://doi.org/10.1016/j.jcma.2017.08.011 PMid:29033374

11. Bourne R, Price H, Taylor H, Leasher J, Keeffe J, Glanville J, Sieving PC, Khairallah M, Wong TY, Zheng Y, Mathew A. New systematic review methodology for visual impairment and blindness for the 2010 Global Burden of Disease study. Ophthalmic Epidemiology. 2013; 20(1):33-9. https://doi.org/10.3109/09286586.2012.741279 PMid:23350553 PMCid:PMC3962016

12. Paul DW, Balakrishnan S, Velusamy A. Rule Based Hybrid Weighted Fuzzy Classifier For Tumor Data. International Journal of Engineering and Technology (UAE). 2018; 7(4):104-8.

13. Balakrishnan S, Janet J, Sujatha K, Rani S. An Efficient and Complete Automatic System for Detecting Lung Module. Indian Journal of Science and Technology. 2018; 11(26):1-5. https://doi.org/10.17485/ijst/2018/v11i26/130559

14. Majerova $H$. The Person in a Situation of Visual Impairment and its Perception and Imagination from the Qualitative Viewpoint. Procedia-Social and Behavioral Sciences. 2017; 237:751-7. https://doi.org/10.1016/j.sbspro.2017.02.117 